\title{
The Iraqi Method of Natural Liquorice as a Mouth Rinse and Its Effect in Patient with Chronic Periodontitis \\ Alaa Omran Ali \\ $\mathrm{BDS}, \mathrm{MSc}$ \\ Rafie mohammed \\ $\mathrm{BDS}, \mathrm{MSc}, \mathrm{PhD}$
}

\section{ABSTRACT}

Background: Chronic periodontitis is an inflammatory disease that affects the supporting tissues of the teeth and it's a common chronic adult condition. Liquorice extract has been shown to effect the periodontium in decreasing its inflammation as a mouth wash.

Aim of the study: Comparative study the effect of liquorice as a mouth rinse in patient with chronic periodontitis.

Materials and Methods : In this study, 15 patients with chronic periodontists (study group) and 15 patient (control group) both received treatment in periodontal department of dentistry college by means of scaling and polishing, the study group in addition received the liquorice mouth rinse in order to study its effect and compare it with the control group. Plaque Index (PI) (sillness and loe 1964), Gingival Index (GI) (sillness and loe 1967) (1) were measured to assess the pattern of periodontal destruction for each patient.

Result and discussion: Liquorice mouth-rinse users demonstrated less amount of plaque (study group) than in the (control group), and less gingival inflammation in the study group than in the control group.

Conclusion: Liquorice extract as a mouth rinse has a an effect on the periodontal tissue health, by decreasing the amount of plaque and gingival inflammation without any side effect it can used for long time and as adjunct with scaling and polishing as treatment of periodontal disease.

CITE THIS ARTCLE

Ali A,Mohammed R.The Iraqi Method of Natural Liquorice as a Mouth Rinse and Its Effect in Patient with Chronic Periodontitis. Iraqi Dent. J. 2016; 38(1):43-47. http://www.iraqidentaljournal.com

\section{INTRODUCTION}

Periodontal diseases are bacterial infections of the gingiva, bone and attachment fibers that support the teeth and hold them in the jaw. The main cause of the diseases is bacterial plaque, a sticky, colorless microbial film that constantly forms on teeth (American Academy of Periodontology American Academy of Periodontology North Michigan Avenue Chicago, Illinois, (2004) (2).

Numerous epidemiological studies have reported a close association between the presence of bacterial plaque and periodontal disease which makes poor oral hygiene the primary etiologic agent in periodontal disease; ${ }^{(3)}$. Microbiological studies indicate that more than 500 distinct microbial species are found in dental plaque $(1994)^{(4)}$. Non bacterial microorganisms that are found in plaque include mycoplasma species, yeasts, protozoa and virus (Newmann, M. G.; Takei, H. H.; Klokkevold. St Louis, Missouri: Saunders, Elsevier Inc. 2006. Vol. 33) ${ }^{(5)}$.

Periodontitis is thought to account for $30-35 \%$ of all teeth extractions while caries and its sequelae for up to $50 \%{ }^{(6)}$.

Chronic periodontitis is generally a slowly progressing of periodontal disease that at any stage may undergo an exacerbation resulting in additional loss of attachment apparatus ${ }^{(6)}$.

\section{Effect of oil puling on plaque and gingivitis:}

Dental caries and periodontal diseases can be effectively prevented and controlled by an effective plaque control method (-2006) ${ }^{(7)}$.

The most wonderful part of oil puling is that it can be performed using any oil easily available at homes. Refined sunflower oil or any other cooking oil for that matter is a common house hold commodity in most of the Indian homes.hence the material for oil pulling is easily accessible to most of the Indian population right at their homes. This is a therapy that can be practiced right at home, without any expense and has a huge storehouse benefits ${ }^{(8)}$.

Various oils like Refined Sunflower oil, Sesame oil, Olive oil etc can be used for Oil Pulling. Liquids from milk and water to extracts of Ghooseberries and mangoes have been used for oil pulling ${ }^{(9)}$.

In the light of the present study it is concluded that Oil Pulling is having dental benefits and ii has resulted in a significant reduction in plaque and gingivitis scores. Hence it can he recommended as an Oral hygiene ${ }^{(10)}$.

\section{Herbal mouthwashes:}

Recently, numerous studies have been conducted to verify the enormous wealth of medicinal plants. These herbal mouthwashes are gaining popularity as they contain naturally occurring ingredients called as Phytochemicals that achieve the desired antimicrobial and anti-inflammatory effects. Herbal formulations may be more appealing because they work without alcohol, artificial preservatives, flavors or colors ${ }^{(11)}$.

\section{Acacia catechu willd:}

$\mathrm{AC}$ is used as mouthwash for mouth, gum and throat diseases like gingivitis, stomatitis. 
The extracts of AC have been reported to have various pharmacological effects like antipyretic, anti-inflammatory, ant diarrhoeal, hypoglycemic, hepatoprotective, antioxidant and antimicrobial activities (12).

\section{Alo Vera (AloeBarbadensis Miller):}

Aloe vera, also known as the true or medicinal aloe, is a species of succulent plant in the genus. The species is frequently used in herbal medicine. Many scientific studies of the use of extracts of Aloevera have been undertaken $(2000)^{(13)}$.Aloe vera contains 75 potentially active constituents: vitamins, enzymes, minerals, sugars, lignin, saponins, salicylic acids and amino acid ${ }^{(14)}$. Aloe vera is found to possess good wound healing activity (Heggers J, kuckcelebi A, Listengarten D, StabenauJ, Ko F, Broemeling LD, etal, 1996) ${ }^{(15)}$. Aloe vera tooth gel demonstrated enhanced antibacterial effect against S. mitis (2009) (16).

\section{Chamomile:}

Throughout history, cultures around the world have made use of chamomile's medicinal benefits. With its anti-inflammatory and antibacterial properties, chamomile can help soothe inflammation from periodontitis and reduce the levels of Unhealthy bacteria in the mouth. Chamomile tea is taken to expose the gums to this herb, or mouthwashes and toothpastes that containing chamomile is a good remedy to overcome periodontal infections (1956) (17).

\section{GlycyrrhizaGlabra(liquorice root) :}

For centuries plants have been used throughout the world as drugs and remedies for various diseases.

Licorice (or liquorice) is a plant of ancient origin and steeped in history. It grows in subtropical climates inEurope, the Middle East, and Western Asia. Licorice extracts and its principle component, glycyrrhizin, have extensive use in foods, tobacco products, and snuff, and in traditional and herbal medicine. Licoriceor Liquorice (Glycyrrhizaglabra), is a perennial herb which possesses sweet taste ${ }^{(18)}$.

Liquorice has extensive pharmacological effects for human being. The most common medical use liquorice is for treating upper respiratory ailments including coughs, hoarseness, sore throat and bronchitis ${ }^{(19)}$. Dried licorice root and herb sometimes used to treat sore throats, respiratory and digestive problems and other disorders - might be an effective agent to fight the bacteria that cause tooth decay and periodontal disease, according to a recent study two compounds found in dried licorice root are effective antibacterial substances that can prevent the growth several major bacteria connected with cavities and gum diseases. licoricidin and licorisoflavan A inhibited two of the major bacteria responsible for dental cavities and two of the bacteria that promote gum disease and licoricidin also inhibited a third gum disease bacterium (20). Licorice root is often used in Chinese traditional medicine and alternative medicine as an additive that enhances the activity of other herbal ingredients. Outside the U.S., it is also being studied for use as an alternative therapy for Hepatitis $\mathrm{C}$ patients. Licorice root is also used as a breath freshening ingredient in some natural tooth pastes the licorice-flavored candies that consumers buy at the store, however, don't contain licorice root. These treats contain anise oil, which has a similar taste.

Licorice root should be used with caution after consulting with a health care professional, since it can have serious side effects and negative interactions with prescription medications (21). Health hazard of Glycyrrhizic acid present in liquorice were evaluated by some researchers ${ }^{(22)}$.

\section{Antibacterial Activities of Phenethyl Isothiocyanate and Its \\ Derivatives against Human Oral Pathogens:}

Major oral health problems include dental caries periodontal diseases, gingival is inflammation and tooth loss (23). These problems are caused by oral microorganisms. A sugar-rich diet together with smoking may cause increasing oral bacterial diseases (24). The effective control of maiororai pathogens such as Actinomyces, Actinobacilhis, Bacteroides, Streptococcus. and Porphvromonas species that cause dental caries and periodontal diseases is thuse an important issue in Korean society ${ }^{(25)}$, Although numerous chemicals and antibiotics have been widely used for the purposes of prevention and disease therapy against oral bacterial diseases, their excessive use can cause an increases in resistance in the target pathogens and serious side effects such as the development of bacterial vomiting, diarrhea and tolerance, teeth strain ${ }^{(26)}$. Studies designed to identify solutions to antibiotics resistance and undesirable side effects have often focused on novel agents against oral pathogens from diverse sources including edible plant extracts and the essential oils of herbal plant (27)

\section{MATERIALS AND METHODS}

This study was carried out during the period from the end of October 2014 till the end of March 2015.

\section{Human sample:}

Subjects included in the study were drawn from patients attending the Department of Periodontics in 
the Collage of Dentistry, University of Baghdad. The study population included thirty subjects with chronic periodontitis with no history of any systemic diseases, the sample included both males and females having in consideration no pregnancy or any hormonal changes that may effect the later in our study. fifteen received liquorice mouth rinse (study group) and and the other fifteen were control group after scaling and polishing for all of them they were followed by two visit the interval between them is one week.

Design of the study:

All the individuals were informed the purposes of the investigation and consented to its protocol. The sample was divided into two groups:

1.(Chronic periodontitis / liquorice mouth rinse users (study group) (group 1) : fifteen patients with chronic periodontitis were assesed to examine there (Plaque Index (PI) (sillness and loe 1964), Gingival Index (GI) (sillness and loe 1967)) (1). And following scaling in the first visit they received the mouth rinse to use it two times daily and followed by a second visit one week later to asses their PI and GI again.

2.(Chronic periodontitis / control group) (group 2): fifteen patients with chronic periodontitis were assesed to examine there (Plaque Index (PI) (sillness and loe 1964), Gingival Index (GI) (sillness and loe 1967)) (1). After first visit of scaling the patients were followed by a second visit to asses the same measurement above.

Materials and instruments:

\section{Instruments:}

- Plane mouth-dental mirrors No.4.

- Marquis colour coded probe.

- Cotton, gloves, and masks.

\section{Methods:}

\section{Clinical examination:}

Oral examination was performed by the same examiner. The collected data include: -

\section{Assessment of Plaque Index (PLI):}

The four surfaces of each tooth except $3^{\text {rd }}$ molar were examined and scored according to plaque index system (Silness\&Loe, 1964) (1).This index was recorded after salivary sample collection.

The criteria for plaque index:

0 : No plaque.

1: A film of plaque adhering to the free gingival margin and adjacent area of the tooth. The plaque may be recognized only by running a probe across the tooth surface.

2: Moderate accumulation of soft deposits within the gingival pocket, on the gingival margin and/ or adjacent tooth surface, which can be seen by the naked eye.

3: Abundance of soft matter within the gingival pocket and/or on the tooth and the gingival margin.

\section{Assessment of Gingival Index (GI):}

The Gingival Index (Loe and Silness, 1967)

(1) was created for the assessment of the gingival condition and records qualitative changes in the gingiva. It scores the marginal and inter proximal tissues separately on the basis of 0 to 3 . The criteria are:

$0=$ Normal gingiva;

$1=$ Mild inflammation - slight change in color and slight edema but no bleeding on probing;

$2=$ Moderate inflammation - redness, edema and glazing, bleeding on probing;

$3=$ Severe inflammation - marked redness and edema, ulceration with tendency to spontaneous bleeding. The bleeding is assessed by probing gently along the wall of soft tissue of the gingival sulcus. The GI of the individual can be obtained by adding the values of the GI for each site on the tooth surface and dividing by the number of sites to be examined examined.

Liqourice mouth rinse preparation. After Through Washing of It, The Iraqi method in preparing the liqourice mouth rinse (ercksos) involve the disolvement of $5 \mathrm{~g}$ in $500 \mathrm{ml}$ for 24 hours as shown the picture above. Then we Fulled it in a Clean water bottle of $330 \mathrm{ml}$.

So the concentration of (ercksos) is $10 \%$ Ready To Be Used Twice Daily.

\section{Statistical Analysis:}

The data were processed and analyzed using the statistics package for social sciences (excel 2013). Both descriptive and inferential statistics were used. 1.Descriptive statistics

a. Statistical tables.

b. Mean

c. Standard deviation (SD).

2.Inferential statistics

Student (t-test).

\section{RESULTS}

\section{Periodontal health results (clinical results). Plaque index (PLI):-}

The descriptive statistics for plaque index were described in Table (3-1), it was clearly shown that the means of plaque index were decreased in (periodontitis/liquorice mouth rinse users) (study group) $=1.15$ as compared with (periodontitis/ control group) $=1.23$. 
Table 1: Descriptive statistics of plaque index in Group I and Group II periodontitis group.

\begin{tabular}{|c|c|c|}
\hline Control group & Study group & Characteristics \\
\hline $1.23 \pm 0.713988$ & $1.15 \pm 0.37295$ & Plaque Index \\
\hline
\end{tabular}

Plaque Index of second Visit
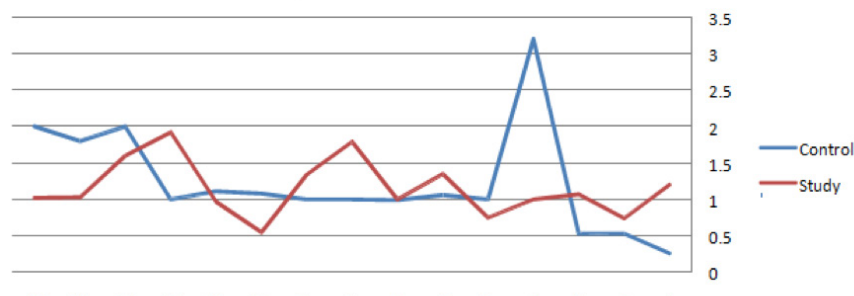

$\begin{array}{llllllllllllll}15 & 14 & 13 & 12 & 11 & 10 & 9 & 8 & 7 & 6 & 5 & 4 & 3 & 2\end{array}$

Figure 1: The relationship between plaque index in study group and control group patients (second visit only)

Table 2: Inter group Comparison of means of plaque index of study group and control group by using t-test

\begin{tabular}{|c|c|c|c|}
\hline \multicolumn{3}{|c|}{ Plaque Index } \\
\hline Sig & p-value & t-test & Group \\
\hline NS & 0.7071 & -0.380 & Group I - Group II \\
\hline
\end{tabular}

NS = No significant Inter group comparison for plaque index showed that there was a no significant difference between Group I and Group II where the p-value was 0.7.

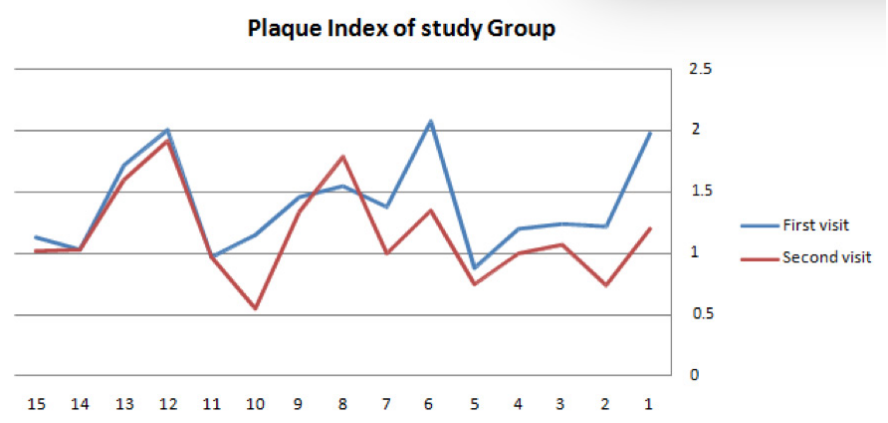

Figure 2: The relationship between plaque index in the first visit as compared with the second visit in study group .

Plaque Index of control Group

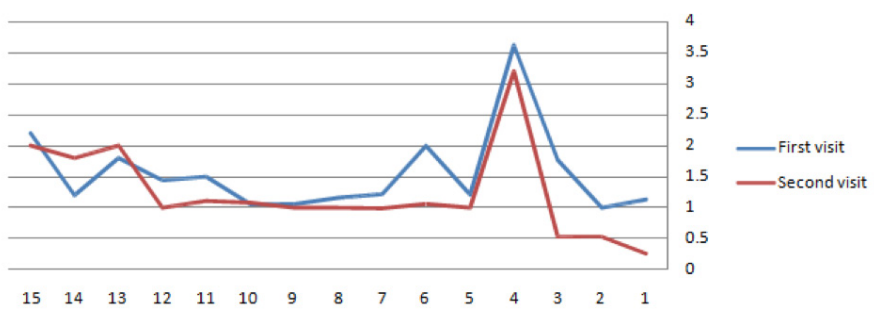

Figure 3: The relationship between plaque index in the first visit as compared with the second visit in the control group.

\section{Gingival Index (GII):}

The descriptive statistics for gingival index were described in the Table (3-4), it was clearly shown that the means of Gingival index were decreased in (periodontitis/ liquorice mouth rinse users) (study group) $=1.02$ as compared with (periodontitis/ control group) $=1.1$.
Table 3: Descriptive statistics of gingival index in Group I and Group II periodontitis groups

\begin{tabular}{|l|c|c|}
\hline Characteristics & Study group & Control \\
\hline Gingival Index & $1.02 \pm 0.130905$ & $1.17 \pm 0.7740$ \\
\hline
\end{tabular}

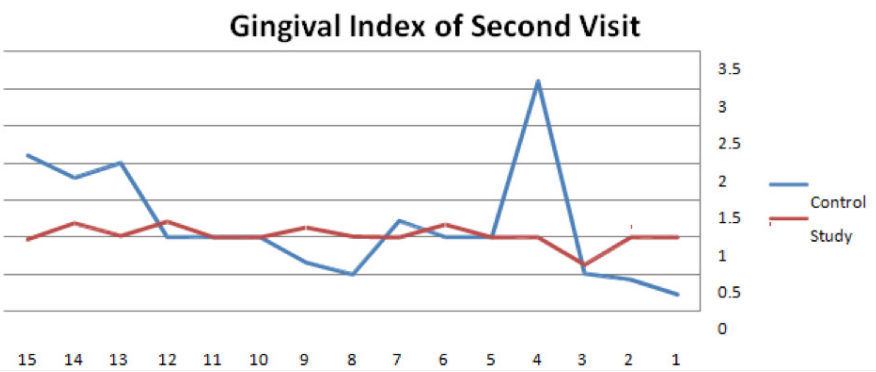

Figure 4: The relationship between gingival index in the first visit as compared with the second visit in the study group.

Table 4: Inter group Comparison of means of Gingival index of study group and control group by using t-test.

\begin{tabular}{|c|c|c|c|}
\hline \multicolumn{4}{|c|}{ Gingival Index } \\
\hline Sig & p-value & t-test & Group \\
\hline HS & 0.477 & -0.729 & Group I-Group II \\
\hline
\end{tabular}

$\mathrm{NS}=$ no significant

Inter group comparison for gingival index showed that there was a no significant difference between study group-control group where the p-value was 0.4 .

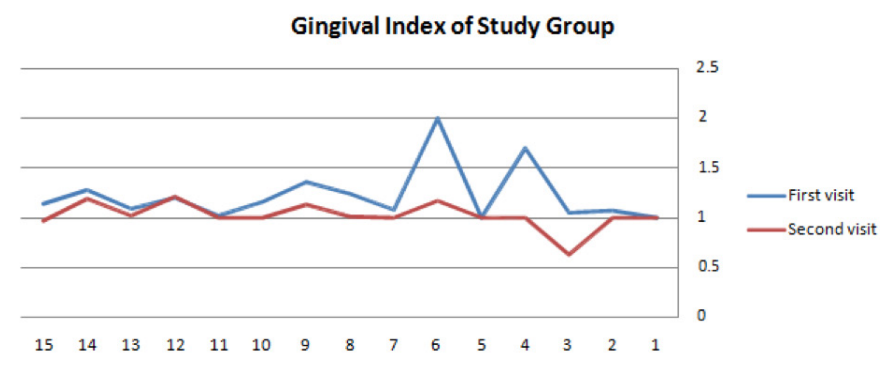

Figure 5: The relationship between gingival index in the first visit as compared with the second visit in the study group.

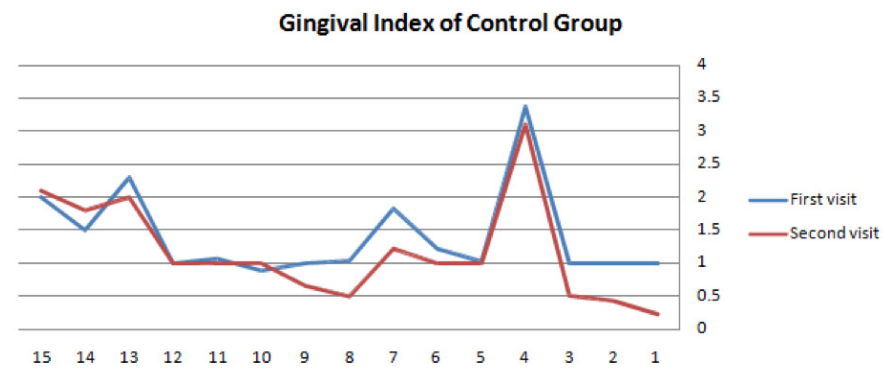

Figure 6: The relationship between gingival index in the first visit as compared with the second visit in the control group .

\section{DISCUSSION}

Considering the short time and the small human sample and the uncooperativeness from the patient part the noticeable reduction effect of plaque and gingival index in our study was of little significant as compared with the control group, so we suggest 
a longer time and larger group for this study to be carried out. But it appear good result in gingival health and that agree with Zhu.j(2006). Though we should mention that in spite of the little reduction, liquorice mouth rinse is a safer and natural substitute to the Chlorhexidine when regarding the side effect, the taste and the safety.

\section{REFERENCES}

1. Plaque Index (PI) (sillness and loe 1964), Gingival Index (GI) (sillness and loe 1967).

2. American Academy of Periodontology.Diabetes and periodontal disease, a two-way relationship.Suite 800 737 North Michigan Avenue Chicago, Illinois, (2004); 60611-2690.

3. Gomes M. S., P. Chagas, D. M. Padilha et al., "Association between self-reported oral health, tooth loss and atherosclerotic burden," Brazilian Oral Research, vol. 26, no. 5, pp. 436-442, 2012.

4. Lockhart P. B., A. F. Bolger, P. N. Papapanou et al., "Periodontal disease and atherosclerotic vascular disease does the evidence support an independent association? A scientific statement from the american heart association," Circulation, vol. 125, no. 20, pp. 2520-2544, 2012.

5. Teeuw W. J., D. E. Slot, H. Susanto et al., "Treatment of periodontitis improves the atherosclerotic profile: a systematic review and meta-analysis,"Journal of Clinical Periodontology, vol. 41, no. 1, pp. 70-79, 2014.

6. Moore WE, Moore LV: The bacteria of periodontal diseases. J. periodontal 2000 1994:5:66.

7. Newmann, M. G.; Takei, H. H.; Klokkevold, P. R. and Carranza, F. A. J. R. Carranza's Clinical Periodontology, 10th edi. St Louis, Missouri: Saunders, Elsevier Inc. 2006. Vol. 33. Pp: 11-137.

8. Lim J., Ji-Hyun Lee, and Su-Jung ShinDiagnosis and treatment of teeth with primary endodontic lesions mimicking periodontal disease: three cases with long-term follow ups. Restor Dent Endod. 2014 Feb; 39(1): 56-62.

9. Wade WG.The oral microbiome in health and disease. Pharmacol Res 2013; 69: 137-143.

10. Dashper S.G., C.A. Seers, K.H. Tan, and E.C. Reynolds Virulence Factors of the Oral Spirochete Treponemadenticola.J Dent Res. 2011 Jun; 90(6): 691-703.
11. Jiang Y, Okoro CA, Oh J, Fuller DL.Sociodemographic and health-related risk factors associated with tooth loss among adults in Rhode Island.Prev Chronic Dis. 2013;10:E45.

12. Dietrich T, Sharma P, Walter C, Weston P, Beck J. The epidemiological evidence behind the association between periodontitis and incident atherosclerotic cardiovascular disease.J ClinPeriodontol. 2013 Apr;40Suppl 14:S70-84.

13. Novak JM.Classification of diseases and conditions affecting the periodontium. In: Newman MG, Takei HH, Klokkevold PR, Carranza FA. Carranza's Clinical Periodontology. 10th edition. Saunders Company 2006: 100-109.

14. Fenesy KE. periodontal disease: an overview for physicians. Mt Sinai J Med; (1987). 65:362-9.

15. Preshaw P.M., A. L. Alba, D. Herrera, S. Jepsen, A. Konstantinidis, K. Makrilakis, and R. Taylor. Periodontitis and diabetes: a two-way relationship. Diabetologia. 2012 Jan; 55(1): 21-31.

16. Spolsky VW Epidemiology of gingival and periodontal disease. In clinical periodontology edt. By Carranza $\mathrm{F}$ and Newman M. 8th ed. WBSaunders, USA, (1996): 61-81.

17. Armitage GC.Periodontal diseases: diagnosis. Ann Periodontol; (1996): 1:37.

18. Kim C.S. Rate of bone loss in furcation-involved molars: A retrospective analysis [In English]. A Thesis presented to the Faculty of the USC Graduate School University of Southern California. partial fulfilment of the requirements for the degree (Master of Science Craniofacial Biology) 2010.

19. Shibata S. Antitumor promoting and anti-inflammatory activities of licorice principles and their modified compounds. Food Phytochemicals II: Teas,Spices and Herbs. 1994; 308-321.

20. Zhu,J.:EP1504763A4, 2006.

21. (Moon,H.S.,Lee,K.H.:US20036503541(2003)).

22. F.C. Størmer, R. Reistad and J. Alexander.Food and Chemical Toxicology; 31 (4), 1993, 303-312 14 Dinesh Dhingra, Milind Parle and S. K. Kulkarni. Journal of Ethnopharmacology 91(2-3) 2004, 361-365

23. (Tasi et al,2006).

24. (Zambom et al, 1996, Phillip, 2006).

25. (Van Oosten et al, 1987; song et al, 2006; Rajasuo).

26. (Javinen et al,1993,song et al 2006).

27. (Shin et al, 2002 ; Kyung et al,2007; Choi et al, 2008). 